\title{
Electrocatalytic Oxidation of NADH in Flow Analysis by Graphite Electrode Modified with 2,6-Dichlorophenolindophenol Salts
}

\author{
Ageliki B. Florou, Mamas I. Prodromidis, Miltiades I. Karayannis, and Stella M. Tzouwara-Karayanni* \\ Department of Chemistry, University of Ioannina, GR-45110 Ioannina, Greece
}

Received: July 15, 1998

Final version: September 14, 1998

\begin{abstract}
The preparation of a 2,6-dichlorophenolindophenol (DCPI) modified graphite electrode is described. DCPI was successfully immobilized by physical adsorption onto a plain graphite electrode (DCPI-CME) and onto graphite electrodes pretreated with lanthanum nitrate (DCPI-La-CME) or thorium nitrate (DCPI-Th-CME). The electrochemical behavior of DCPI-CME was extensively studied using cyclic voltammetry. The electrochemical redox reaction of DCPI was found to be fairly reversible at low coverage with $E^{\mathrm{o}^{\prime}}=+55 \mathrm{mV}(\mathrm{vs}$. $\mathrm{Ag} / \mathrm{AgCl} / 3 \mathrm{M} \mathrm{KCl})$ at $\mathrm{pH} 6.5$. A $\mathrm{pK}_{\mathrm{a}}$ value of $5.8 \pm 0.1$ for immobilized form of DCPI is determined from the intersection of the lines in the plot $E^{\mathrm{o}}$ vs. $\mathrm{pH}$. The current $I_{\mathrm{p}}$ has a linear relationship with the scan rate up to $1200 \mathrm{mV} \mathrm{s}^{-1}$, which is indicative for very fast electron transfer kinetics. The calculated value of the standard rate constant is $k^{\mathrm{o}}=18 \pm 4 \mathrm{~s}^{-1}$. No decrease of either the anodic or the cathodic current of the cyclic voltammogram was observed after 500 runs of successive sweeps. The influence of the morphology of the electrode surface on the electrochemical behavior of the DCPI-CME was studied and a mathematical model is proposed, which partly describes the dependence of the geometrical area of the electrode surface on the grid of the emery paper. The modified electrodes were mounted in a flow-injection manifold, poised at $+60 \mathrm{mV}(\mathrm{vs} . \mathrm{Ag} / \mathrm{AgCl} / 3 \mathrm{M} \mathrm{KCl})$ and a catalytic current due to the oxidation of NADH was observed reducing thus the oxidation overpotential of NADH for about $400 \mathrm{mV}$. Interference from various reductive species present in real samples was investigated. The repeatability was $1.2 \% \operatorname{RSD}(n=10$ for $0.1 \mathrm{mM}$ NADH). The sensor showed good operational and storage stability.
\end{abstract}

Keywords: Electrocatalytic oxidation of NADH, DCPI chemically modified electrodes, Cyclic voltammetry, Flow injection analysis

\section{Introduction}

The oxidation of NADH at bare electrodes takes place at high overvoltage ranging from 450 to $1100 \mathrm{mV}$ depending on the material of the electrode [1,2]. It was early recognized that the reaction is highly irreversible and suffers from interference from other oxidizable species at such high potentials. For concentrations higher than $0.1 \mathrm{mM} \mathrm{NADH}$ the reaction also involves radical intermediates resulting in electrode fouling. Furthermore the major product formed $\mathrm{NAD}^{+}$is an inhibitor of the direct electrode process $[2,3]$.

The large number of problems associated with the oxidation of NADH initiated investigations on redox mediators such as quinones, catechols, redox dyes, metal comlexes and organic conducting salts [4-14], which have been used successfully to oxidize NADH. The reaction of NADH with DCPI in solution was studied by stopped-flow spectrophotometry and was found very fast with a completion time of a few tenths of a second [15]. Aerobic oxidation of NADH in the presence of NADH oxidase has also been reported [16]. The use of mediators or mediator-modified electrodes for bioelectrochemistry in general and amperometric biosensors specifically was reviewed recently by Gorton [17].

The decrease of the overvoltage is mainly dictated by the formal potential $E^{\mathrm{o}^{\prime}}$ of the mediator. Low potentials minimize the electrode fouling and also prevent interfering reactions. Nevertheless one of the commonest problems encountered is the poor stability of the modified electrodes [18].

Our objective in this article is to exploit the excellent electrochemistry of the DCPI redox couple, to describe the surface attachment of the redox mediator on plain and lanthanum or thorium pretreated porous graphite electrodes and to investigate the electrocatalytic properties of the sensor. The effect of the surface morphology on the analytical characteristics of the electrode was also investigated. The simple preparation and the very good stability made this electrode a promising candidate for its use as a probe in dehydrogenase based biosensors.

\section{Experimental}

\subsection{Reagents}

2,6-Dichlorophenolindophenol sodium salt dihydrate $\left(\mathrm{C}_{12} \mathrm{H}_{6} \mathrm{Cl}_{2}\right.$ $\mathrm{NNaO}_{2} \cdot \mathrm{H}_{2} \mathrm{O}$, Cat. No 103028) was obtained from Merck (Darmstadt, Germany) and was used without further purification. Lanthanum nitrate hexahydrate $\left[\mathrm{La}\left(\mathrm{NO}_{3}\right)_{3} \cdot 6 \mathrm{H}_{2} \mathrm{O}\right.$, cat. No L-2388] and thorium nitrate pentahydrate $\left[\mathrm{Th}\left(\mathrm{NO}_{3}\right)_{4} \cdot 5 \mathrm{H}_{2} \mathrm{O}\right.$, cat. No 108162] were supplied by Sigma-Aldrich Chemie GmbH (Steinheim, Germany) and Merck, respectively. Potassium hexacyanoferrate(III) $\left[\mathrm{K}_{3} \mathrm{Fe}(\mathrm{CN})_{6}\right.$, Cat. No 29610] was obtained from BDH (Poole, Dorset, UK). $\beta$-Nicotinamide-adenine-dinucleotide disodium salt, reduced form (NADH, cat. No N-8129) was purchased from Sigma Chemical Co (St. Louis, USA). The NADH solution was daily prepared in the working buffer. All other chemicals were of analytical grade from Merck and Sigma.

\subsection{Apparatus}

All electrochemical experiments were conducted with a computer controlled potentiostat, the Autolab Electrochemical Analyzer (Eco Chemie, Utrecht, The Netherlands).

The flow injection experiments were carried out using an inhouse fully automated flow injection manifold. A detailed description of the FIA-manifold and the electrochemical detector was published earlier [19]. The working electrode was a graphite rod (RW0001, 6.5 mm i.d., Ringsdorf-Werke, Germany).

Cyclic voltammetry was performed with a voltammetry cell (VC2, BAS, West Lafayette, IN, USA) using a graphite rod as working electrode, whose sides were covered with parafilm for ensuring a constant active surface, an $\mathrm{Ag} / \mathrm{AgCl} / 3 \mathrm{M} \mathrm{KCl}$ reference electrode (BAS) and a Pt wire as auxiliary electrode with a gold connecting pin (BAS). All experiments were carried out at $25^{\circ} \mathrm{C}$. 


\subsection{Procedure}

The surface coverage $\Gamma$ of the modifier was evaluated from the integrated anodic peak of the cyclic voltammograms in the range -200 to $+300 \mathrm{mV}$ (vs. $\mathrm{Ag} / \mathrm{AgCl} / 3 \mathrm{M} \mathrm{KCl}$ ), at $50 \mathrm{mV} \mathrm{s}^{-1}$, corrected for the background current [20]. The anodic and cathodic current integrals were equal. The supporting electrolyte was a $0.25 \mathrm{M}$ phosphate buffer in $1 \mathrm{M} \mathrm{KCl}$ at $\mathrm{pH} \mathrm{3-8.}$

The total effective electrode area of the graphite working electrode was determined by performing double step chronocoulometry on hexacyanoferrate (a species of known diffusion coefficient, $D_{\mathrm{o}}=7.6 \times 10^{-6} \mathrm{~cm}^{2} \mathrm{~s}^{-1}$ ). The working electrode was immersed in the voltammetry cell containing $4 \mathrm{mM}$ hexacyanoferrate in $1 \mathrm{M} \mathrm{KCl} \mathrm{pH} 3$ [21].

The applied potential for the flow injection measurements was $+60 \mathrm{mV}$ (vs. $\mathrm{Ag} / \mathrm{AgCl} / 3 \mathrm{M} \mathrm{KCl}$ ). After the potential had been applied to the CME, the background current was allowed to decay to a stable value under continuous flow $(45-70 \mathrm{~min})$. The noise was of the order $0.5 \mathrm{nA}$. The carrier $(0.05 \mathrm{M}$ phosphate buffer in $0.05 \mathrm{M}$ $\mathrm{KCl}, \mathrm{pH}$ 6.5) was continuously pumped at a flow rate of $0.36 \mathrm{~mL} \mathrm{~min}^{-1}$. Samples of NADH were injected with a $130 \mu \mathrm{L}$ injection loop. The peak height of the current response was taken as a measure of the NADH concentration.

\subsection{Preparation of the Modified Electrodes}

Spectroscopic graphite rods were polished on emery paper of various grits (Struers, Salzburg, Austria), then polished against a lens cleaning tissue (No 105 Whatman) and finally they were thoroughly washed with double-distilled water. They were dried at $60{ }^{\circ} \mathrm{C}$ for $30 \mathrm{~min}$, heated in a muffle furnace at $700^{\circ} \mathrm{C}$ for $90 \mathrm{~s}$ (to remove any small particles from the surface area) and allowed to cool in a desiccator [8]. To avoid electrical contact between the sides of the electrodes and the solution, the sides of the working electrodes were covered with Parafilm before the electrochemical experiment. Especially for the chronocoulometric experiments the electrodes were pressfitted into a Teflon tube in order to insure only linear diffusion.

\subsubsection{Direct Adsorption of DCPI Molecules}

The surface modification was made by applying an appropriate volume of a solution of DCPI in acetone on the surface of the electrode with a micropipette. The solvent was allowed to evaporate at ambient temperature for $15 \mathrm{~min}$, followed thoroughly by washing with distilled water. Depending on the desired surface coverage different volumes and concentrations of the DCPI solutions were used. Cyclic voltammetry experiments were carried out at low coverages $(10 \mu \mathrm{L}$ of $0.4 \mathrm{mM}$ DCPI solution). For analytical purposes in order to achieve higher coverage $20 \mu \mathrm{L}$ of a $0.01 \mathrm{M}$ DCPI solution in acetone was applied.

\subsubsection{Adsorption onto Pretreated Graphite Electrodes}

The modified electrodes were prepared by applying first on the flat circular top of the electrode $60 \mu \mathrm{L}$ of a $0.01 \mathrm{M} \mathrm{La}\left(\mathrm{NO}_{3}\right)_{3}$ or $\mathrm{Th}\left(\mathrm{NO}_{3}\right)_{4}$ solution in acetone applied in three successive aliquots. The solution was allowed to evaporate for $1 \mathrm{~h}$ and the eventually dry electrode was washed thoroughly with distilled water. A $20 \mu \mathrm{L}$ aliquot of a $0.01 \mathrm{M}$ solution of DCPI in acetone was placed to the graphite surface and the electrode was left for $1 \mathrm{~h}$ to air dry. During this time a green-blue layer formed due to the production of the DCPI-lanthanum or DCPI-thorium salts on the surface [22]. Finally the electrode was washed with the working buffer. The sensor was kept dry in air at $4{ }^{\circ} \mathrm{C}$ in a refrigerator.

\section{Results and Discussion}

\subsection{Determination of the Effective Electrode Area}

Figure 1 shows four pictures of electrodes polished with different emery paper taken with a scanning electron microscope (SEM, J. SM. 840A, JEOL). It is obvious that the surfaces of the graphite electrodes exhibit high heterogeneity and are quite complex. Many cavities, grooves and stacked flakes at differing sizes constitute the surface area. As it can be seen from the pictures, the surface becomes smoother as the grit number of the emery paper increases. When extra fine emery paper (grit $\geq 2400$ ) is used, the surface becomes glossy and smooth. Only a few small cavities can be observed. The shape of the cavities is irregular indicating removal of material during the polishing procedure. The actual surface area available for adsorption is much greater than the geometrical one.

The total active surface area was evaluated applying double step chronocoulometry, from an initial value of $+0.6 \mathrm{~V}$ to a final value of $0 \mathrm{~V}$. The chronocoulometric response is described by the integrated Cottrell equation:

$$
Q_{\mathrm{t}}=\left(2 n F A C D_{\mathrm{o}}^{1 / 2} t^{1 / 2}\right) / \pi^{1 / 2}
$$

where $Q_{\mathrm{t}}$ is the total charge passed, $C$ is the concentration of hexacyanoferrate, $A$ is the active electrode area, $D_{\mathrm{o}}$ is the diffusion coefficient of hexacyanoferrate (the other terms have their usual meaning). The experimental data was transformed into a plot of $Q$ vs. $t^{1 / 2}$ (Anson plot), whose slope is $2 n F A C D_{\mathrm{o}}^{1 / 2} / \pi^{1 / 2}[23,24]$. From the results shown in Table 1 it can be concluded that the active surface area is decreased as the emery paper grit is increased with a tendency to reach a constant value using emery paper whose grit number is larger than 1200 . It was observed that the quality of the polishing determines partly the value of RSD of the evaluated electrode surface area. The results were confirmed from the evaluation of the background (capacitive) currents obtained by cyclic voltammetry in blank solutions of $0.1 \mathrm{M} \mathrm{KCl} \mathrm{pH} 3$ (data not shown). For the graphite rods polished with 80, 240 and 600 grit emery paper the background currents show a continuous decrease probably due to the penetration of the electrolyte into the pores of the rods creating thus a labyrinthic environment [25]. The background currents of the electrodes polished with emery paper $\geq 1200$ grit give smaller background currents of approximately the same shape. This can be explained by the normalization of the shape and size of the cavities and grooves as the grain sizes are getting smaller. At these grain sizes the surface of the electrode could be assumed as an uniform area consisted of cavities (cups) as shown in Figure 2. If we consider that the polishing of the carbon electrode area creates pores which have the shape of sphere-zones of radius $r$, as indicated in Figure 2, from geometrical considerations the total surface area $A_{\mathrm{T}}$ of the electrode, according to the proposed model is given by Equation 2:

$$
A_{\mathrm{T}}=n(2 \pi r h)+\left(\pi R^{2}-n \pi \rho^{2}\right)
$$

where $n, R, r, h$ and $\rho$ are the total number of the pores, the radius of the electrodes cross-sectional, the radius of the hemisphere, the height of the hemisphere's zone and its cross-sectional radius, respectively.

As the polishing proceeds to finer emery paper, the value of $\rho$ and $h$ converge to zero and the total area of the electrode reaches its macroscopic geometrical value $\pi R^{2}$. This was confirmed with the experimental results presented in Table 1, which indicates that as the grit number increases the active surface area of the electrode reaches a constant value.

Emery paper of grit 1200 was selected for polishing the 

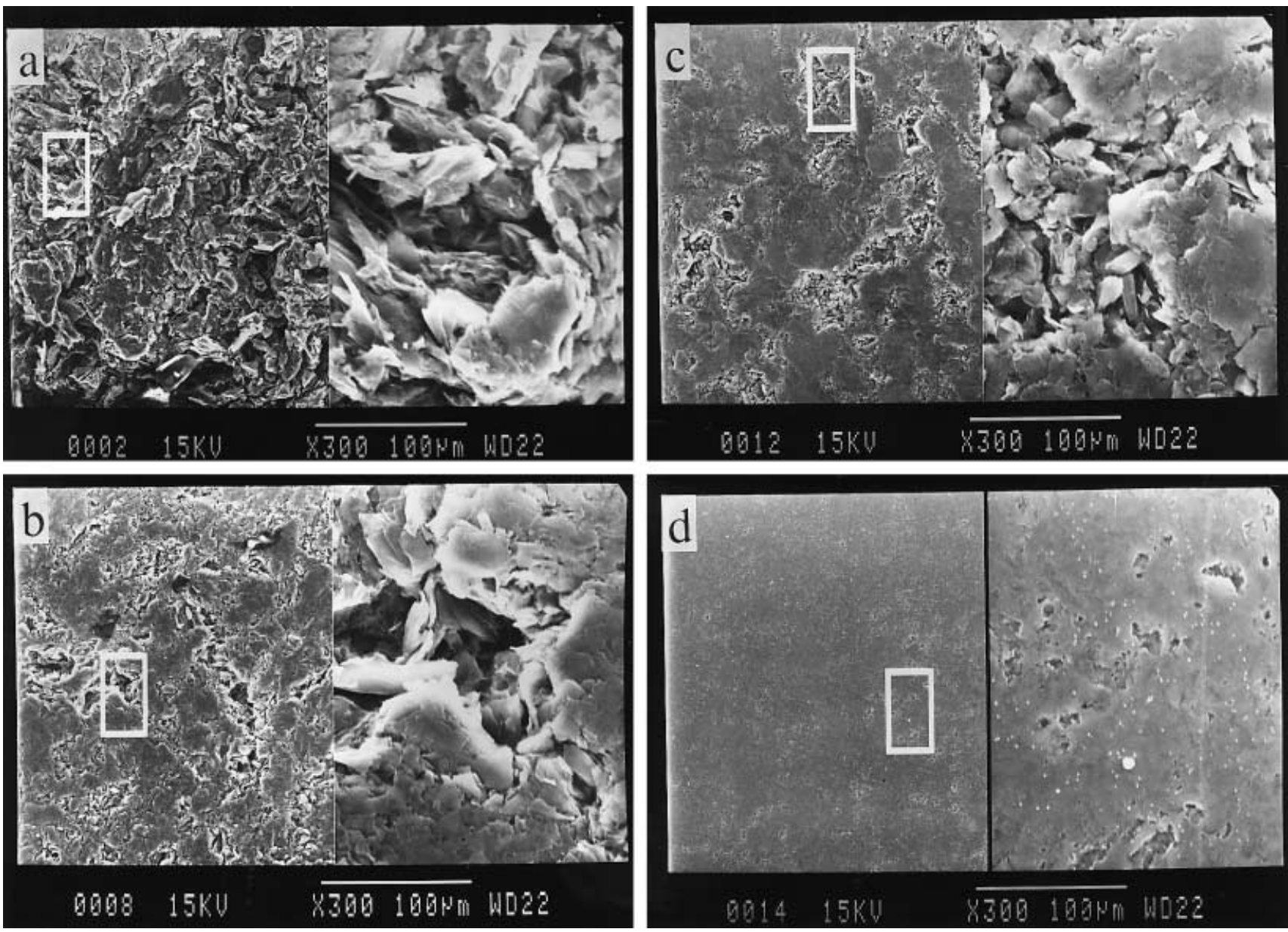

Fig. 1. Scanning electron microscopy pictures of four graphite electrodes polished with emery papers of different grain size (a: 80 grit, b: 600 grit, c: 1200 grit and d: 2400 grit). The left and the right part of each picture is magnified according to the scale bars on to the pictures.

electrodes in most of the experiments, because they exhibited an excellent voltammetric behavior when DCPI molecules were adsorbed onto their surfaces (Table 1). Electrodes polished with rougher emery paper show poor stability, high peak potential separation $\Delta E_{\mathrm{p}}$ and large values of width at half peak height $E_{\mathrm{fwhm}}$. This behavior can be explained assuming immigration of the mediator inwards to unoccupied adsorption sites in the large pores of the graphite, e.g., volume elements (cavities, grooves) of $20 \AA$ deep, where the concentration of the mediator, in this interfacial solution, could reach the value of $1 \mathrm{M}$. Parallel reactions such as disproportonations and dimerizations may also occur. As reported by Murray [20], reactions in the concentrated interfacial solution may be slowed considerably by constraints on mobility or collisional orientation imposed by the immobilized state of the molecule. The adsorbed DCPI molecules on electrodes polished with finer emery papers $\left(2400,4000\right.$ grit) exhibited $\Delta E_{\mathrm{p}}$ and $E_{\mathrm{fwhm}}$ values higher than those observed by pretreatment with emery paper of grit 1200. The uniformity of the surface of the electrodes polished with the finer emery papers is probably leading, to more sites available for the adsorption of the modifier (see Fig. 1). Hence, the observed surface coverages are larger resulting strong interactions among the immobilized molecules and side way

Table 1. Electrochemical results and variation of the surface area of graphite electrodes, polished with emery paper of different grits. DCPI-CME (10 $\mu \mathrm{L}$ of $0.4 \mathrm{mM}$ acetone DCPI solution). $0.25 \mathrm{M}$ Phosphate buffer in $1 \mathrm{M} \mathrm{KCl}, \mathrm{pH} 6.5$.

\begin{tabular}{lcccllll}
\hline $\begin{array}{l}\text { Emery paper } \\
\text { grit }\end{array}$ & $\begin{array}{l}\text { Number of } \\
\text { scans }\end{array}$ & $\Delta I_{\mathrm{a}} \%[\mathrm{a}]$ & $\Delta I_{\mathrm{c}} \%[\mathrm{a}]$ & $\begin{array}{l}\Delta E_{\mathrm{p}}[\mathrm{b}] \\
{[\mathrm{mV}]}\end{array}$ & $\begin{array}{l}E_{\mathrm{fwhm}}[\mathrm{b}] \\
{[\mathrm{mV}]}\end{array}$ & $\begin{array}{l}\text { Surface area }[\mathrm{c}] \\
{\left[\mathrm{cm}^{2}\right]}\end{array}$ & $\begin{array}{l}\text { Surface coverage }[\mathrm{b}] \\
{\left[\mathrm{nmol} \mathrm{cm}^{-2}\right]}\end{array}$ \\
\hline 80 & 500 & -14.10 & -10.13 & 25 & 66 & $0.59 \pm 0.18$ & 1.72 \\
$240(58.2 \pm 2.0 \mu \mathrm{m})[\mathrm{d}]$ & 50 & -24.78 & -9.35 & 35 & 82 & $0.44 \pm 0.03$ & 2.50 \\
$600(22.7 \pm 1.0 \mu \mathrm{m})[\mathrm{d}]$ & 50 & -42.48 & -27.76 & 39 & 94 & $0.38 \pm 0.01$ & 2.29 \\
$800(21.8 \pm 1.0 \mu \mathrm{m})[\mathrm{d}]$ & 50 & -12.06 & -6.61 & 25 & 73 & $0.37 \pm 0.05$ & 1.83 \\
$1000(18.3 \pm 1.0 \mu \mathrm{m})[\mathrm{d}]$ & 500 & 0 & -2.16 & 15 & 56 & $0.35 \pm 0.03$ & 1.22 \\
$1200(15.2 \pm 1.0 \mu \mathrm{m})[\mathrm{d}]$ & 500 & 0 & -0.95 & 9 & 53 & $0.33 \pm 0.01$ & 1.03 \\
$2400(10.0 \pm 0.5 \mu \mathrm{m})[\mathrm{d}]$ & 500 & -1.62 & -1.79 & 28 & 60 & $0.34 \pm 0.03$ & 1.63 \\
$4000(5.0 \pm 0.5 \mu \mathrm{m})[\mathrm{d}]$ & 500 & 0 & 0 & 25 & 60 & $0.34 \pm 0.03$ & 2.20 \\
\end{tabular}

[a] Relative change after the noted number of scans. [b] Calculated from the 10th scan. [c] The values were calculated by chronocoulometry. The indicated error is the standard deviation for $\mathrm{n}=7$ different plain electrodes. Electrolyte: $4 \mathrm{mM} \mathrm{K}_{3} \mathrm{Fe}(\mathrm{CN})_{6}$ in $1 \mathrm{M} \mathrm{KCl}, \mathrm{pH}$ 3. [d] The values in brackets are the grain size in $\mu \mathrm{m}$ which correspond to the grit of emery paper. For grit 80 the manufacturer does not give any grain size number. 


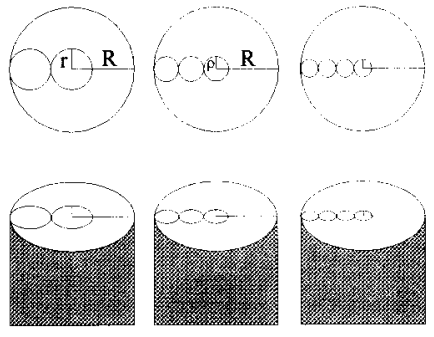

(a)

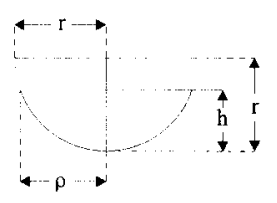

(b)
Fig. 2. Schematic representation of the graphite electrodes surfaces illustrating a) the increase of the number of the pores during the polishing procedure and $\mathrm{b}$ ) the radius $r$ of the hemispheric pores, the height of its zone $h$ and the radius $\rho$ of its cross-section.

reactions due to dimerizations or disproportionations [20] (see Table 1).

\subsection{Electrochemistry of the Adsorbed DCPI}

Cyclic voltammetry with DCPI-CMEs in $0.25 \mathrm{M}$ phosphate buffer in $1 \mathrm{M} \mathrm{KCl}, \mathrm{pH} 6.5$ solutions produces well behaved peaks with the anodic and cathodic waves almost mirror-images of each other (Fig. 3). Since the anodic and cathodic peaks of the adsorbed DCPI are symmetrical, it is permissible to calculate the formal potential $E^{\mathrm{o}^{\prime}}$ by taking the mean of the position of the two [24]. Formal potentials of $54 \mathrm{mV}, 55 \mathrm{mV}, 57 \mathrm{mV}$ and $59.5 \mathrm{mV}$ (vs. $\mathrm{Ag}$ / $\mathrm{AgCl} / 3 \mathrm{M} \mathrm{KCl})$ were found for solutions of DCPI $\left(E_{\mathrm{sol}}^{\mathrm{o}^{\prime}}\right)$, immobilized DCPI $\left(E_{\mathrm{DCPI}}^{\mathrm{o}}\right)$, immobilized lanthanum salt $\left(E_{\mathrm{DCPI}-\mathrm{La}}^{\mathrm{o}^{\prime}}\right)$ and immobilized thorium salt $\left(E_{\mathrm{DCPI}-\mathrm{Th}}^{\mathrm{o}^{\prime}}\right)$ of DCPI, respectively. Comparison of the formal potentials shows that interactions between the immobilized molecule and the surface of the electrode, to which it is attached, do not strongly perturb the electronic structures of the immobilized molecule and its electron transfer products. The peak potential separation $\Delta E_{\mathrm{p}}$ is moderate as expected for a surface-immobilized redox species [20]. Values of $9-30 \mathrm{mV}$ were obtained for surface coverages $\Gamma$ between 0.52 and $3.12 \mathrm{nmol} \mathrm{cm}^{-2}$ and scan rate $50 \mathrm{mV} \mathrm{s}^{-1}$ (Fig. 4, curve a). Increasing the scan rate up to $700 \mathrm{mV} \mathrm{s}^{-1}$ the $\Delta E_{\mathrm{p}}$ values moderate between 17 and $47 \mathrm{mV}$ while the $I_{\mathrm{a}} / I_{\mathrm{c}}$ ratio present only small deviations from the theoretical value 1 . For scan rates 800 to $2000 \mathrm{mV} \mathrm{s}^{-1}$ the $\Delta E_{\mathrm{p}}$ varies between 47 to $81 \mathrm{mV} \mathrm{s}^{-1}$ and the $I_{\mathrm{a}} / I_{\mathrm{c}}$ ratio values are near the value 1 .

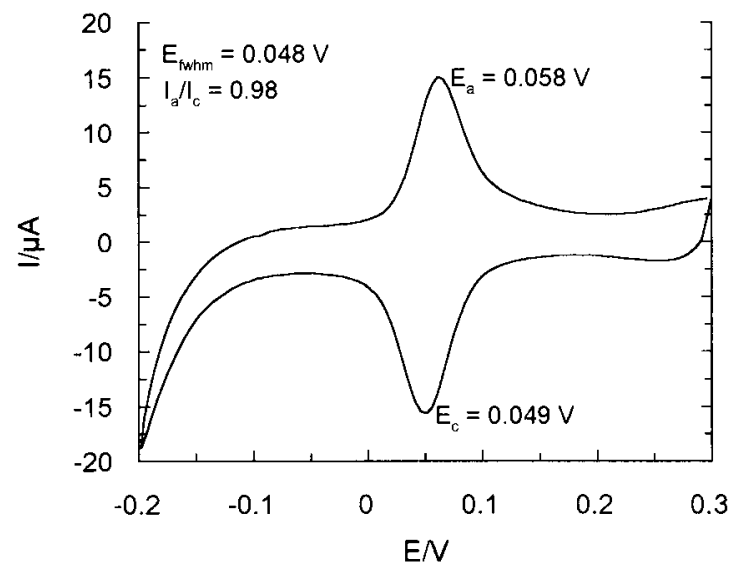

Fig. 3. Cyclic voltammogram of a DCPI-modified electrode in a $0.25 \mathrm{M}$ phosphate buffer in $1 \mathrm{M} \mathrm{KCl}, \mathrm{pH} 6.5$. Surface coverage: $0.52 \mathrm{nmol} \mathrm{cm}^{-2}$; scan rate: $50 \mathrm{mV} \mathrm{s}^{-1}$.

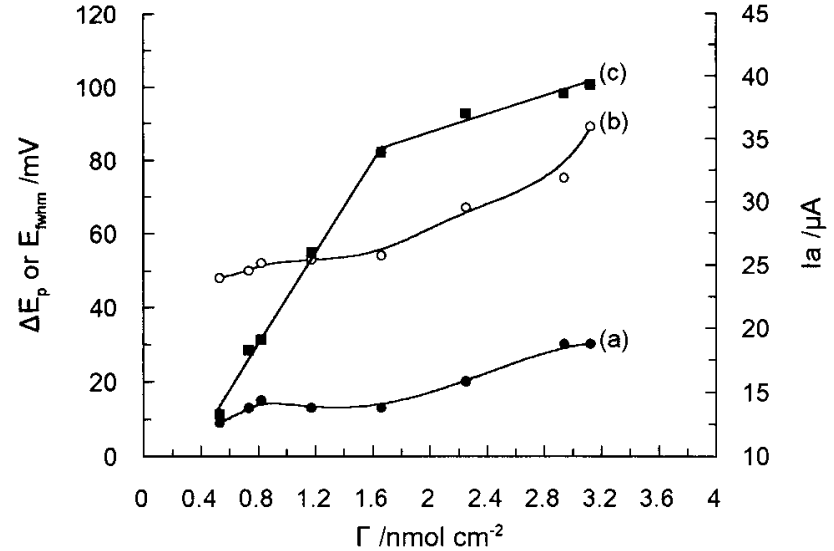

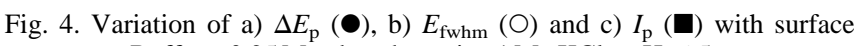
coverage. Buffer: $0.25 \mathrm{M}$ phosphate in $1 \mathrm{M} \mathrm{KCl}, \mathrm{pH} 6.5$; scan rate: $50 \mathrm{mV} \mathrm{s}^{-1}$.

Figure 4a shows that the peak separation is $<15 \mathrm{mV}$ for coverages less than $1.8 \mathrm{nmol} \mathrm{cm} \mathrm{cm}^{-2}$. This indicates that the electron transfer is fast [20], which is to be expected for a $\pi$-electron overlap between the adsorbed compound and the underlying graphite structure. The peak separation increases, however, as the surface coverage increases further reaching a maximum value of $30 \mathrm{mV}$ for a coverage of $3.12 \mathrm{nmol} \mathrm{cm}^{-2}$ indicating the formation of multilayers and networks [26]. The width at half peak height $E_{\text {fwhm }}$ for coverages less than $1.8 \mathrm{nmol} \mathrm{cm}^{-2}$ is $<52 \mathrm{mV}$, which is close to the theoretical value (Fig. 4, curve b). In the ideal case where the adsorption satisfies the Langmuir isotherm the predicted values of $\Delta E_{\mathrm{p}}$ and $E_{\mathrm{fwhm}}$ are $0 \mathrm{mV}$ and $90.6 / n \mathrm{mV}$, respectively, where $n$ is the number of electrons taking part in the redox conversion [20, 24]. However, deviations from the ideal values of $\Delta E_{\mathrm{p}}$ and $E_{\mathrm{fwhm}}$ seem to be usual for redox-modified electrodes, even at low coverages and sweep rates because of the interactions between the DCPI molecules or their interaction with the support. Broader and flatter peaks can be also attributed to the influence of heterogeneity of the electrode [27].

The peak current, $I_{\mathrm{p}}$, for an adsorbed compound is given by the following equation

$$
I_{\mathrm{p}}=\left(n^{2} F^{2} / 4 R T\right) \Gamma A v
$$

where $A$ is the surface area, $\Gamma$ the surface coverage and $v$ the sweep rate . The $n$-value can be calculated from Equation 3 provided the other quantities are known only if the Langmuir model is followed.

A plot of the peak current versus coverage reveals two linear segments instead of a single straight line (Fig. 4, curve c).The slope modification is observed for surface coverages $>1.8 \mathrm{nmol} \mathrm{cm}^{-2}$. Conclusively Figure 4 (curve a, b and c) shows, that there is a critical value of surface coverage $\left(1.8 \mathrm{nmol} \mathrm{cm}^{-2}\right)$ over which the interactions between the adsorbed molecules resulted in voltammetric peak-broadening, indicative of the formation of multilayers. A plot of $I_{\mathrm{p}}$ vs. $v$ for CME-DCPI shows a linear relation up to $1200 \mathrm{mV} \mathrm{s}^{-1}$ as predicted theoretically for adsorbed species (Fig. 5a). The experimental data so far support a model in which the redox compound is adsorbed on the electrode surface. The proposed sensor behaves well and shows an extended linearity for high sweep rates in contrast to the majority of other mediators, which deviate from linearity already by scan rates higher than 200 to $300 \mathrm{mV} \mathrm{s}^{-1}$ $[4,5,6,10]$. Above $1200 \mathrm{mV} \mathrm{s}^{-1}$ the relationship becomes linear only when plotted versus the square root of $v$ (Fig. 5b) indicating mass transport limited within the films [24]. Diffusion of species with fast electrochemical reactions is expected to give a linear relation for $I_{\mathrm{p}}$ against the square root of the sweep rate. This is 


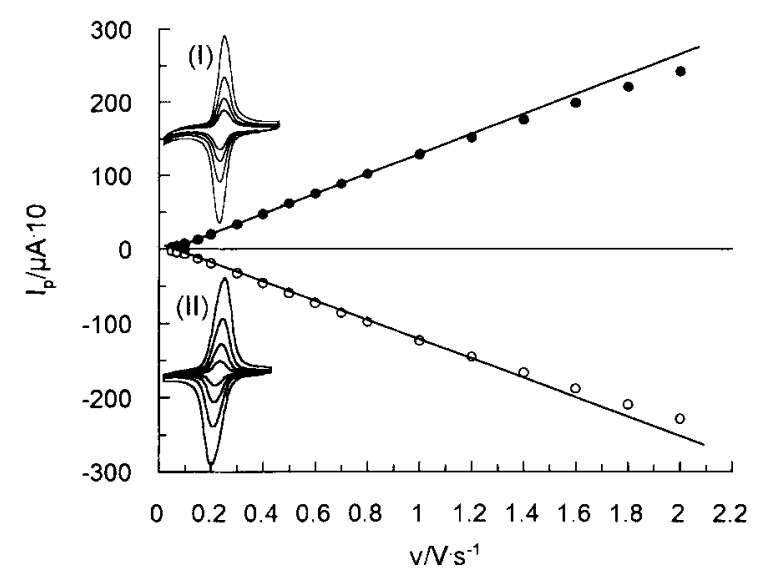

(a)

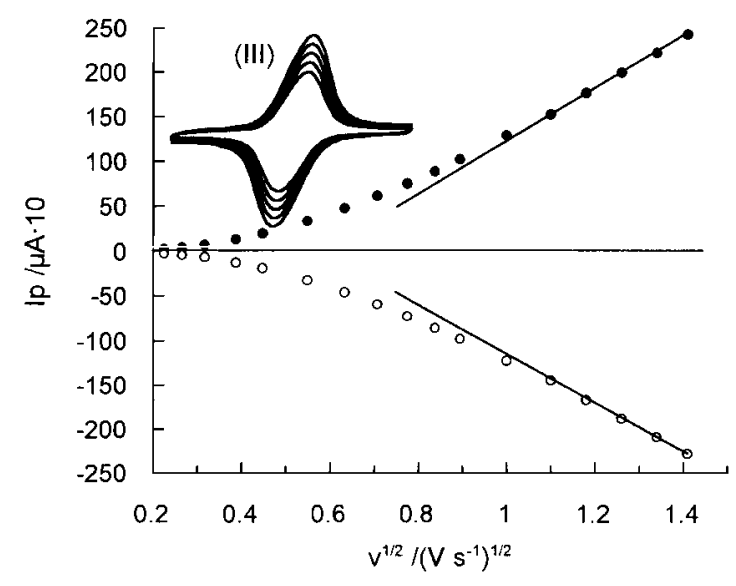

(b)

Fig. 5. Variation of $I_{\mathrm{p}}$ with a) the scan rate and b) the square root of scan rate. Embedding cyclic voltammograms represent the experimental data for scan rates: (I) $50,70,100,150 \mathrm{mV} \mathrm{s}^{-1}$, (II) $200,400,700,1000 \mathrm{mV} \mathrm{s}^{-1}$ and (III) $1200,1400,1600,1800,2000 \mathrm{mV} \mathrm{s}^{-1}$. Buffer: $0.25 \mathrm{M}$ phosphate in $1 \mathrm{M} \mathrm{KCl}$, pH 6.5; surface coverage: $1.62 \mathrm{nmol} \mathrm{cm}^{-2}$.

specifically true in a regime of high surface coverage, high sweep rates or low buffer capacities, where local $\mathrm{pH}$ changes could occur, resulting in increases of $\Delta E_{\mathrm{p}}$. Under these high sweep rates the diffusional step dominates the procedure. The DCPI's redox reaction involves proton mobility (see Eqs. 4 and 5) that results increasing dependence on the diffusional sweep rate even at low surface coverages [6].

The number of the participating electrons in the redox reaction can be evaluated from the slope of the linear part in Figure $5 \mathrm{a}$ (Eq. 3) as $1.70 \pm 0.02$. This result suggests two successive single electron transfer steps rather than two electron transfer reaction in one step. The $n$-value can be also deduced from the $E_{\mathrm{fwhm}}=90.6 / n$ for scan rates near $0 \mathrm{mV} \mathrm{s}^{-1}$. This approach gave a $n$-value of 1.88 for scan rate $20 \mathrm{mV} \mathrm{s}^{-1}$. Higher scan rates yielded lower $n$ values because of the influence of electrochemical kinetics on the peak current [28]. The most likely explanation for the fractional $n$ value, also supported by theoretical considerations, is that $I_{\mathrm{p}}$ decreases while $E_{\text {fwhm }}$ increases due to interactions between the adsorbed molecules [21, 27, 28]. It is therefore reasonable to assume that 2 electrons participate in the redox reaction of DCPI.

The apparent electrochemical rate constant $k^{\mathrm{O}}$ was calculated from Tafel diagrams according to the method described by Laviron

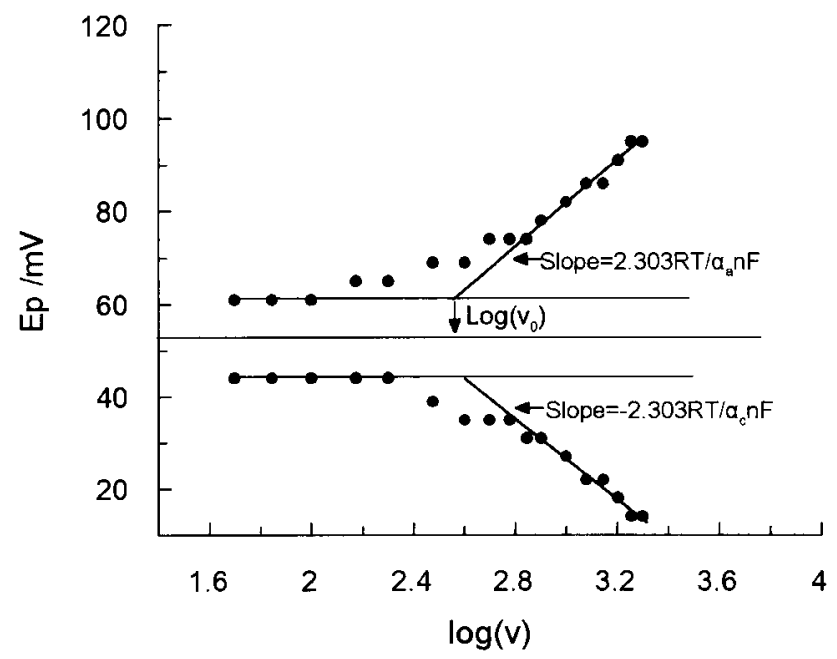

Fig. 6. Dependence of $E_{\mathrm{p}}$ on $\log (v)$. Buffer: $0.25 \mathrm{M}$ Phosphate in $1 \mathrm{M} \mathrm{KCl}$, $\mathrm{pH}$ 6.5; surface coverage: $1.62 \mathrm{nmol} \mathrm{cm}^{-2}$; graphical calculation of the critical potential scan rate, $v_{\mathrm{o}}$.

[29]. For high scan rates, theory predicts a linear dependence of $E_{\mathrm{p}}$ upon $\log (v)$, which can be used to extract the kinetic parameters $\alpha_{\mathrm{a}}$, $\alpha_{\mathrm{c}}$ (anodic and cathodic transfer coefficients) and $k^{\mathrm{o}}$ from the slopes and intercepts of such plots, with the reversible formal potential, respectively. Figure 6 illustrates the procedure used for evaluating $\alpha_{\mathrm{a}}, k^{\mathrm{o}}$ from the anodic and $\alpha_{\mathrm{c}}, k^{\mathrm{o}}$ from the cathodic partial reaction. The slope of the linear segment is equal to $-2.303 R T / \alpha_{\mathrm{c}} n F$ for the cathodic and 2.303RT/ $\alpha_{\mathrm{a}} n F$ for the anodic peak. The evaluated values for the coefficients $\alpha_{\mathrm{a}}$ and $\alpha_{\mathrm{c}}$ are 0.66 and 0.65 , respectively. The sum of transfer coefficients $\alpha_{\mathrm{c}}$ and $\alpha_{\mathrm{a}}$ is seen to deviate quite significantly from its normal value of 1 . Similar results have been earlier reported by Sharp and co-workers for Pt-ferrocene electrodes [30]. If the value $\alpha_{\mathrm{c}}=0.5$ is used, the relative error on $k^{\mathrm{o}}$ is at most $6 \%$, because the difference $\Delta E_{\mathrm{p}}$ does not depend very much on the transfer coefficient [29]. A mean value of $k^{\mathrm{o}}=18 \pm$ $4 \mathrm{~s}^{-1}$ was evaluated from all the extracted experimental data applying equation $k^{\mathrm{o}}=2.303 \alpha_{\mathrm{c}} n F v_{\mathrm{o}} / R T$. The observed $k^{\mathrm{o}}$ values of well-known mediators $[5,6,10]$ moderate between 4 and $10 \mathrm{~s}^{-1}$ obviously smaller than the DCPI's apparent rate constant. Further to other evidence the large value of $k^{\mathrm{o}}$ also justifies fast establishment of the equilibrium.

The dependence of the formal redox potential $E^{\mathrm{o} /}$ for adsorbed DCPI on the $\mathrm{pH}$ was investigated by cyclic voltammetry. Figure 7 shows $E^{\mathrm{o}^{\prime}}$ as a function of $\mathrm{pH}$. The $E^{\mathrm{o} \prime}$ value was taken as the average value of the anodic and cathodic peak potentials at scan rate $20 \mathrm{mV} \mathrm{s}^{-1}$, where no kinetic effects would adversely distort the peak current [20].

A $\mathrm{pK}_{\mathrm{a}}$ value of $5.8 \pm 0.1$ for the reduced DCPI was found from the intersection of the two straight lines with slopes $-57 \mathrm{mV}(\mathrm{pH}$ unit $)^{-1}$ in the acid region and $-81 \mathrm{mV}$ (pH unit) $)^{-1}$ in the more alkaline region. The change in the slope from -57 to $-81 \mathrm{mV}(\mathrm{pH}$ unit) ${ }^{-1}$ is caused by the oxidized form of DCPI. The smaller experimental values of the slopes compared to the theoretical,

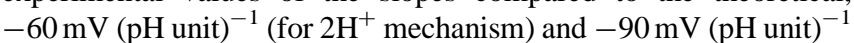
(for $3 \mathrm{H}^{+}$mechanism) [7] are probably due to the coexistence of different species at each $\mathrm{pH}$, suggested by their distribution diagrams [31]. The results of this study are in accordance with the reaction scheme:

$$
\begin{array}{ll}
\text { For } \mathrm{pH}<5,8 & \mathrm{D}^{-}+2 \mathrm{H}^{+}+2 \mathrm{e}^{-} \rightleftarrows \mathrm{DH}_{2}^{-} \\
\text {For } \mathrm{pH}>5,8 & \mathrm{D}^{-}+3 \mathrm{H}^{+}+2 \mathrm{e}^{-} \rightleftarrows \mathrm{DH}_{3}
\end{array}
$$

where $\mathrm{D}^{-}$is the oxidized form of DCPI at high $\mathrm{pH}$. 


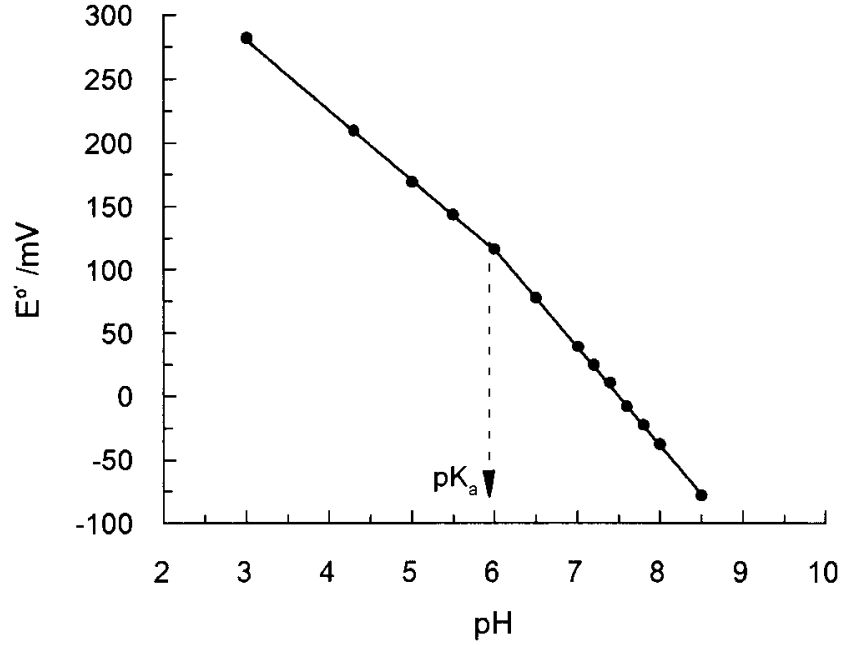

Fig. 7. Formal potentials $E^{\mathrm{o}^{\prime}}$ for adsorbed DCPI as a function of $\mathrm{pH}$. Scan rate $20 \mathrm{mV} \mathrm{s}^{-1}$. Buffer: $0.25 \mathrm{M}$ phosphate in $1 \mathrm{M} \mathrm{KCl}, \mathrm{pH}$ 6.5; surface coverage: $0.82 \mathrm{nmol} \mathrm{cm}^{-2}$

The DCPI molecule can exist in different forms described by the equilibrium schemes shown in Scheme 1.

The $\mathrm{pH}$ dependence of the formal potential was also investigated in solutions of DCPI leading to a $\mathrm{pK}_{\mathrm{a}}$ value of $5.6 \pm 0.1$ for the oxidized form. The calculated $\mathrm{pKa}$ value is in an excellent agreement with previously reported vales $[31,32,33]$.The strong adsorption of the DCPI molecules on the graphite surface may cause only a small shift of the $\mathrm{pK}_{\mathrm{a}}$ value according to previous investigations on adsorbed molecules participating in acid-base equilibria [7, 32].

\subsection{Electrocatalytic Oxidation of NADH}

The electrocatalysis by the DCPI-modified electrode observed in a buffer solution containing $3 \mathrm{mM} \mathrm{NADH}$ is demonstrated in Figure 8. Scan a) is a cyclic voltammogram of the modified electrode in a buffer solution without and scan b) with NADH. Scan c) is a voltammogram of NADH solution taken with a plain carbon electrode for comparison. The NADH oxidation on the plain electrode (curve c) appears at $+450 \mathrm{mV}$ in agreement with earlier reports $[12,13]$. Oxidation of NADH on the DCPI-modified electrodes gives a peak at $+60 \mathrm{mV}$ (curve b), very close to the formal potential of the adsorbed mediator (curve a). The anodic current is increased several times due to the presence of the reduced

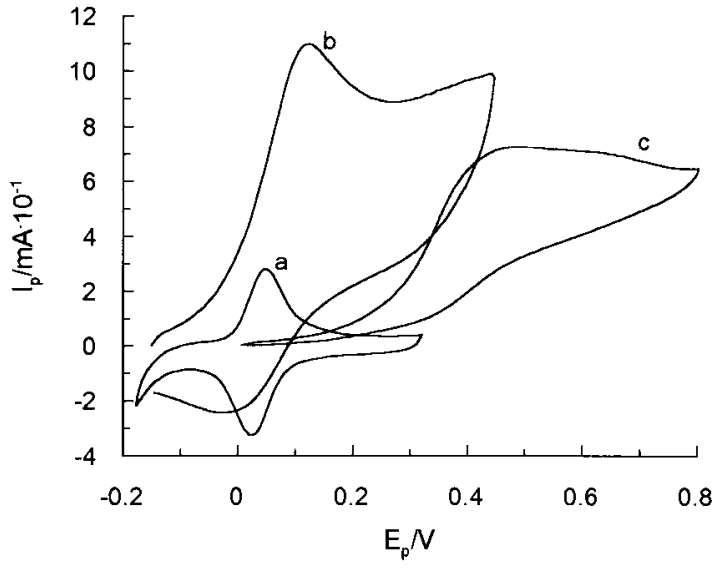

Fig. 8. Cyclic voltammograms illustrating the catalytic oxidation of NADH mediated by adsorbed DCPI. Curve a) DCPI-La-CME in buffer solution $\left(\Gamma=0.8 \mathrm{nmol} \mathrm{cm}{ }^{-2}\right)$. Curve b) the same DCPI-La-CME in a buffer solution containing $3 \mathrm{mM}$ NADH. Curve c) graphite electrode (plain) in a buffer solution containing $3 \mathrm{mM} \mathrm{NADH}$. Scan rate: $50 \mathrm{mV} \mathrm{s}^{-1}$; buffer: $0.25 \mathrm{M}$ phosphate in $1 \mathrm{M} \mathrm{KCl}, \mathrm{pH} 6.5$.

coenzyme, whereas the cathodic current is decreased accordingly. This effect can be explained by taking into account diffusion of NADH on the surface of the electrode and reduction of the oxidized form of the mediator, which is then re-oxidized electrochemically during the sweep, according to the reaction:

$$
\mathrm{D}^{-}+\mathrm{NADH}+\mathrm{H}^{+} \rightleftarrows \mathrm{DH}_{2}^{-}+\mathrm{NAD}^{+}
$$

which demonstrates the electrocatalytic oxidation of NADH to $\mathrm{NAD}^{+}$.

The applicability of the DCPI-modified electrode as a sensor was investigated by flow injection analysis (FIA). The main target of the DCPI-La-CME and DCPI-Th-CME was merely the improvement of the analytical properties of the plain DCPI sensor since the solubilities of the DCPI-La and DCPI-Th salts were already known to be low $\left(K_{\mathrm{sp}}<10^{-10}\right)$ [22]. The electrodes DCPI- CME, DCPI-La$\mathrm{CME}$ and DCPI-Th-CME mounted in a flow through amperometric cell and used for these experiments exhibit normal surface coverages between 2.5 to $7 \mathrm{nmol} \mathrm{cm}{ }^{-2}$.

Parameters such as working $\mathrm{pH}$ and flow rates of the reagents were optimized. The different analytical conditions were implemented with a standard solution of $0.1 \mathrm{mM}$ NADH.

The $\mathrm{pH}$ dependence for the NADH response is shown in Fig. 9. It can be seen that the optimum pH for DCPI and DCPI-La modified electrodes is 6.5 which was used for further experiments.

Several flow rates in the range of $0.15-0.80 \mathrm{~mL} \mathrm{~min}^{-1}$ were<smiles>O=C1C=CC(=Nc2cc(Cl)c(OCOc3ccc(N=C4C=C(Cl)C(=O)C(Cl)=C4)cc3)c(Cl)c2)C=C1</smiles><smiles>O=C1C(Cl)=CC(=Nc2ccc(O)cc2)CC1Cl</smiles>

Oxidized Form

Reduced Form

Scheme 1. 


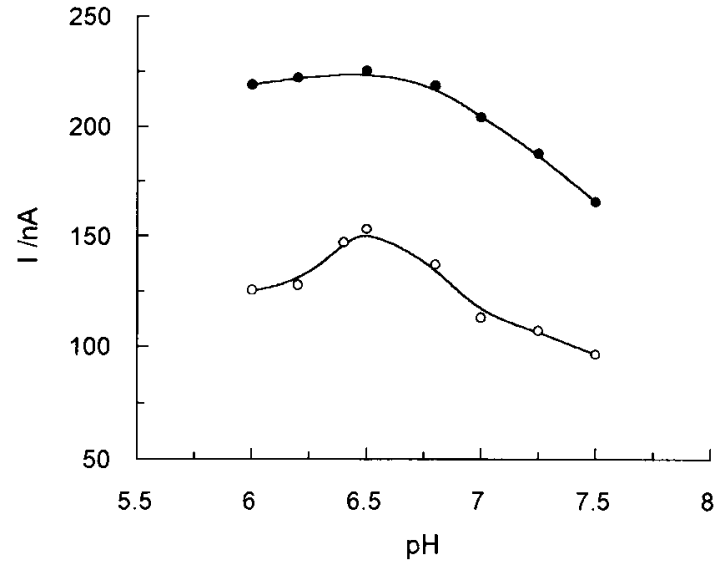

Fig. 9. pH profile of the DCPI $(O)$ and the DCPI-La $(\bullet)$ chemical sensor. Buffer: $0.05 \mathrm{M}$ phosphate in $0.05 \mathrm{M} \mathrm{KCl}$; applied potential: $60 \mathrm{mV}$; flow rate: $0.36 \mathrm{~mL} \mathrm{~min}^{-1}$.

tested. An overall flow rate of $0.36 \mathrm{~mL} \mathrm{~min}^{-1}$ gave fairly high peak intensities and satisfactory sampling throughput $\left(25\right.$ samples $\left.\mathrm{h}^{-1}\right)$. A sample volume of $130 \mu \mathrm{L}$ was selected for performing the experiments, which compensates small peak broadening and fairly high sensitivity.

Good linearity 0.04 to $0.4 \mathrm{mM}$ for the DCPI-CME $(r=0.999)$, 0.004 to $0.4 \mathrm{mM}$ for the DCPI-La-CME $(r=0.999)$ and 0.008 to $0.2 \mathrm{mM}$ for the DCPI-Th-CME $(r=0.999)$ was achieved for the modified carbon electrodes. The detection limits (signal/noise ratio 3) were $0.01,0.002$ and $0.004 \mathrm{mM}$ for DCPI-CME, DCPI-La-CME and DCPI-Th-CME, respectively. The enhancement of sensitivity expressed with the slope $1.692 \mu \mathrm{A} \mathrm{mM}^{-1}$ for the DCPI-La-CME compared to the slope $1.120 \mu \mathrm{A} \mathrm{mM}^{-1}$ of DCPI-CME is shown in Figure 10. The reason of the increased signals and linearity range for the DCPI-La-CME may be attributed to the enhanced strength of adsorption and the low solubility of the DCPI-lanthanum salt. The sensitivity when the DCPI-Th-CME was applied was slightly greater (slope: $1.138 \mu \mathrm{A} \mathrm{mM}^{-1}$ ) compared to the sensitivity of DCPI-CME. The relative standard deviation for a standard solution of $0.1 \mathrm{mM}$ NADH was found $1.2 \% \mathrm{RSD}(n=10)$ and $1.7 \% \mathrm{RSD}$ $(n=7)$ for DCPI- and DCPI-La-CME, respectively.

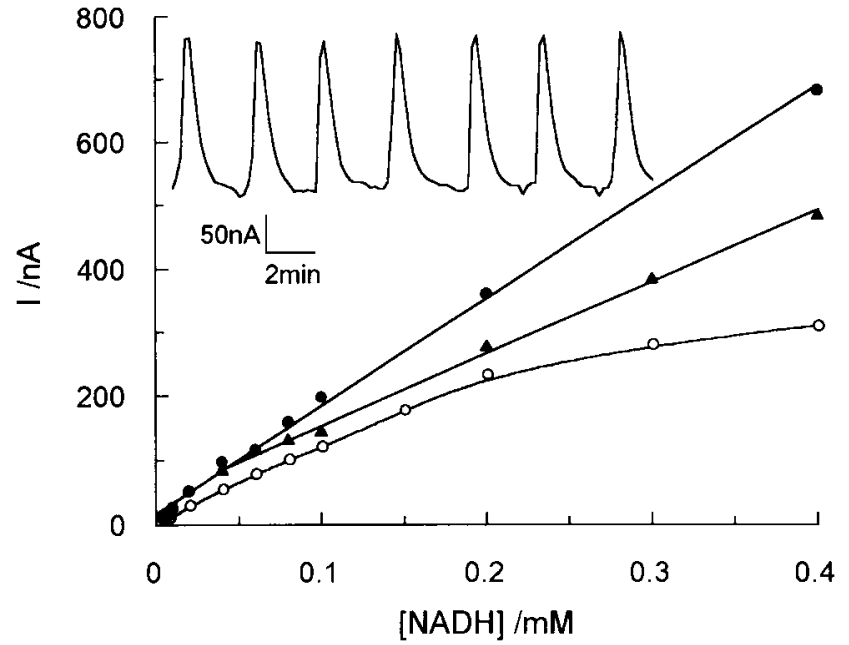

Fig. 10. Calibration plots for the determination of NADH using: DCPI $(\boldsymbol{\Delta})$, DCPI-La $(\bullet)$ and DCPI-Th $(O)$ modified electrodes. Buffer: $0.05 \mathrm{M}$ phosphate in $0.05 \mathrm{M} \mathrm{KCl} \mathrm{pH} 6.5$; applied potential: $60 \mathrm{mV}$; flow rate: $0.36 \mathrm{~mL} \mathrm{~min}^{-1}$. The upper part of the figure indicates the repeatability of the results for $0.1 \mathrm{mM}$ of NADH with the DCPI-La-CME.

\subsection{Interferences}

Interference from various reductive species present in real samples was investigated by applying the method of mixed solutions in the presence of $0.1 \mathrm{mM} \mathrm{NADH}$. Interferants were added at concentrations much higher than those normally present in the real samples. The relative responses for $2 \mathrm{mM}$ paracetamol, $2 \mathrm{mM}$ dopamine, $2 \mathrm{mM}$ ampicilline, $2 \mathrm{mM}$ uric acid, $2 \mathrm{mM}$ oxalic acid, $1 \mathrm{mM}$ theophylline, $1 \mathrm{mM}$ glutathione and $0.5 \mathrm{mM}$ cysteine were 99, 102, 98, 101, 99, 95, 104 and $110 \%$, respectively, compared to the response shown with pure solution of $0.1 \mathrm{mM}$ NADH taken as $100 \%$. Only ascorbic acid $(0.2 \mathrm{mM})$ and sodium sulfide $(0.2 \mathrm{mM})$ exhibit significant positive interferences $(320 \%$ and $190 \%$, respectively). Since sodium sulfide is rarely present in real NADH samples its interference is not important. The large increase in the observed signal in the case of ascorbic acid is due to its high reactivity with the DCPI $\left(\mathrm{k}=5.6 \times 10^{4} \mathrm{~mol}^{-1} \mathrm{~s}^{-1}\right)[34]$ and to its direct oxidation on graphite electrodes even at applied potentials lower than $+50 \mathrm{mV}$. This problem is acute for the majority of CME's and could be either minimized by pretreatment of the samples in alkaline media [35] or eliminated using ascorbate oxidase [36].

\subsection{Stability of the Sensor}

The stability of the adsorbed DCPI was verified by monitoring the amount of the active substance after 500 successive sweeps. The amount of DCPI remaining on the electrode surface depends markedly on the $\mathrm{pH}$ of the solution as illustrated in Table 2. As it can be seen, the sensor provides a remarkable stability at $\mathrm{pH} 6.5$ attributed to the strength of adsorption of DCPI on the spectrographic graphite minimizing thus its desorption with time. No decrease of both the anodic or cathodic currents was observed at $\mathrm{pH} 6.5$ (data not shown). At other $\mathrm{pH}$ values desorption into the bulk of the solution may be one additional mechanism behind the apparent decreased stability of the adsorbed compound.

The operational stability of the sensors was studied by continuous exposure to the flow stream. As a result the final DCPI-CME activity (current response vs. initial current response $\times 100 \%$ ) was $70 \%$, whereas the final DCPI-La-CME activity was still $90 \%$ after $6 \mathrm{~h}$ of continuous operation. The decrease in activity is due to the leaching out effect of DCPI from the DCPI-CME surface, as is evident from the experimental observations that the decrease of peak height was related more to the operating time of the electrode in flow stream and not to the number of NADH injections. The DCPI-La-CME seems to be more stable because of the low solubility of the DCPI-La salt.

The sensors displayed good storage stability if stored dry at $4{ }^{\circ} \mathrm{C}$, when not in use. The DCPI-CME retained $75 \%$ and $60 \%$ of its initial activity after 1 week and 2 weeks of storage respectively.

Table 2. Stability of the DCPI-CME in phosphate buffer solutions of different $\mathrm{pH}$. The stability of the DCPI-modified electrodes is measured with the estimated amount of DCPI attached to the surface of the graphite electrode. Buffer: 0.25 phosphate in $1 \mathrm{M} \mathrm{KCl}$.

\begin{tabular}{lccc}
\hline$p H$ & \multicolumn{2}{l}{$\Gamma \Gamma_{\text {init }} \%$ after } & \\
\cline { 2 - 4 } & $15 \min$ & $90 \min$ & $180 \mathrm{~min}$ \\
\hline 5.5 & 100 & 98 & 98 \\
6.5 & 100 & 100 & 100 \\
7.0 & 90 & 80 & 75 \\
7.4 & 90 & 75 & 65 \\
7.8 & 65 & 50 & 45 \\
\hline
\end{tabular}


After 1 week the DCPI-La-CME exhibited $90 \%$ and after 2 weeks of storage $75 \%$ of its initial activity.

\section{Acknowledgements}

The authors thank Associate Professor G. Pilidis for valuable discussion concerning the protolytic equilibrium schemes of DCPI molecule. The electron microscope pictures of the spectroscopic graphite electrodes were taken by the group in the Scanning Electron Microscopy Laboratory of the Aristotle University of Thessaloniki. This work was partially supported by the General Secretariat of Research and Development of the Greek Government project PENED '95, No 15.

\section{References}

[1] L. Gorton, E. Csöregi, E. Dominguez, J. Emnéus, G. Jönsson-Pettersson, G. Marko-Varga, B. Persson, Anal. Chim. Acta 1991, 250, 203.

[2] H. Jaegfeldt, J. Electroanal. Chem. 1980, 110, 295.

[3] L. Gorton, J. Chem. Soc., Faraday Trans., 1 1986, 82, 1245.

[4] C. Ueda, D. Chi-Sing Tse, T. Kuwana, Anal. Chem. 1982, 54, 850.

[5] H. Jaegfeldt, T. Kuwana, G. Johansson, J. Am. Chem. Soc. 1983, 105, 1805

[6] L. Gorton, A. Torstensson, H. Jaegfeldt, G. Johansson, J. Electroanal. Chem. 1984, 161, 103

[7] B. Persson, L. Gorton, J. Electroanal. Chem. 1990, 292, 115.

[8] M. PoláŠek, L. Gorton, R. Appelqvist, G. Marko-Varga, G. Johansson, Anal. Chim. Acta 1991, 246, 283

[9] B. Persson, H. Sui Lee, L. Gorton, T. Skotheim, P. Bartlett, Electroanalysis 1995, 7, 935.

[10] B. Persson, J. Electroanal. Chem. 1990, 287, 61.

[11] W.J. Albery, P.N. Bartlett, J. Chem. Soc., Chem. Commun. 1984, 1, 234.

[12] B.F. Yon Hin, C.R. Lowe, Anal. Chem. 1987, 59, 2111
[13] L. Angnes, C.M.N. Azevedo, K. Araki, H.E. Toma, Anal. Chim. Acta 1996, $329,91$.

[14] M. I. Prodromidis, S.M. Tzouwara-Karayanni, M.I. Karayannis, P. Vadgama, A. Maines, Analyst 1996, 121, 435.

[15] M.I. Karayannis, P.A. Siskos, Anal. Chim. Acta 1982, 136, 339.

[16] M. Fumio, Y. Soichi, K. Tatsuo, Anal. Sci. 1991, 7, 871.

[17] L. Gorton, Electroanalysis 1995, 7, 23.

[18] P.N Bartlett, P. Tebbutt, R.G. Whitaker, Prog. Reaction Kinetics 1991, 16 , 55.

[19] M.I. Prodromidis, A.B. Tsibiris, M.I. Karayannis, J. Autom. Chem. 1995, 17 187.

[20] R.W. Murray, in Electroanalytical Chemistry, Vol. 13 (Ed: A.J. Bard), Marcel Dekker, New York 1984, pp. 191-368.

[21] Handbook of Electroanalytical Products, Bioanalytical Systems, Inc. 1997, No. 133 , p. 81

[22] P. Veltsistas, S. Tzouwara-Karayanni, M.I. Karayannis, 2nd Workshop of Biomedical Engineering Action of the European Community on Chemical Sensors for In Vivo Monitoring, Firence, 12-15 Nov. 1989, paper No 21.

[23] W.R. Heineman, Current Separations 1986, 7, 58.

[24] A.J. Bard, L.R. Faulkner, Electrochemical Methods: Fundamentals and Applications, Wiley, New York 1980.

[25] R.L. McCreery in Electroanalytical Chemistry, Vol. 17 (Ed: A.J. Bard), Marcel Dekker, New York 1991, pp. 221-375.

[26] E. Laviron, L. Roullier, C. Degrand, J. Electroanal. Chem. 1980, 112, 11.

[27] E. Laviron, L. Roullier, J. Electroanal. Chem. 1980, 115, 65.

[28] E. Laviron, in Electroanalytical Chemistry, Vol. 12 (Ed: A.J. Bard), Marcel Dekker, 1982, pp. 53-157.

[29] E. Laviron, J. Electroanal Chem. 1979, 101, 19.

[30] M. Sharp, M. Petersson, K. Edström, J. Electroanal. Chem. 1979, 95, 123.

[31] C.N. Konidari, S.M. Tzouwara-Karayanni, L.E. Bowman, M.I. Karayannis, Talanta 1992, 39, 863.

[32] R. Narayanaswamy, F. Sevilla, Anal. Chim. Acta 1986, 189, 365.

[33] J.M. Ottaway, in Indicators (Ed: E. Bishop), Pergamon Press, Oxford 1972, pp. $472-476$.

[34] M.I. Karayannis, Talanta 1976, 23, 27.

[35] S.M. Tzouwara-Karayanni, M.I. Karayannis, S.R. Crouch, Food Chem. 1993, 48,95 .

[36] K. Matsumoto, T. Tsukatani, Y. Okajima, Electroanalysis 1995, 4, 801 